body will still accept food for the time being. Miss Allabach made certain experiments which seem to disprove Nagel's idea that these reactions are due to judgment on the part of Metridium. The food was removed from the œsophagus. The tentacles behaved as before. The food had not been digested and Metridium, therefore, could not judge by experience that the food was not good. The conclusion is that the tentacles become fatigued.

The problem is a significant one. The method, so far as it goes, is good. Both suffer because Miss Allabach's report is inadequate and not well organized.

Clara Jean Weidensali.

UNIVERSITY OF CHICAGO.

\title{
REPORTS.
}

\section{MEETING OF EXPERIMENTAL PSYCHOLOGISTS.}

On April 18 and 19 the third annual meeting of Experimental Psychologists was held in the Yale laboratory. No formal program was made up before the meeting and no papers were read. Informal reports were given by representatives of the different laboratories, of investigations under way, and of those recently completed but not yet published. Following each report there was much free discussion. On Wednesday evening the members dined at the Graduate Club and spent the evening in an informal smoker.

On Wednesday morning Professor Titchener reported for Cornell, and characterized the work of that laboratory as being in general an experimental reëxamination of much of the matter which has been current in psychology. He specifically mentioned three lines of investigation: first, a more exact introspective analysis of the feelings; second, a like description of the commoner organic sensations designated in every-day speech by such expressions as 'a lump in the throat'; and third, a series of tests of mental ability. After a discussion the morning session was concluded by the reading of a report from the Chicago laboratory in the absence of its authors, Drs. Carr and Allen. This paper reported a case of voluntary localization of objects in depth through change of accommodation while convergence remained the same, and of voluntarily holding an object at a given localization while convergence varied. The discussion of this report extended into the afternoon and brought out a report by Professor Heinrich, of Krakau, on similar work done by him in Poland. His 
general conclusion, in opposition to the conclusion of Drs. Carr and Allen, was that changes in accommodation affect localization only indirectly through the resulting changes in the retinal image.

The Wednesday afternoon session was occupied with reports from Professors Sanford and Dodge and a short report from Mr. Loomis of the Yale laboratory. Professor Sanford reported investigations in learning as the chief subject of research at present going on in the Clark laboratory. He mentioned particularly the learning process which is involved in the use of the typewriter, and in playing chess, with an accompanying introspective analysis of this process. He also mentioned studies on the favorite number, as it appears in guessing contests, and of the reasoning processes as revealed, for example, in the solution of problems of division. Professor Dodge reported an investigation on the influence of the pre-exposure and post-exposure fields on the length of time necessary for the recognition of visual impressions. He found that the length of time was markedly different for differences in the complexity and illumination of the pre-exposure and post-exposure fields, and concluded, in general, that the change is due to a peripheral process. Mr. Loomis reported graphic records of the movements made by various subjects in lifting weights subject to the familiar illusion which appears when the weights are of different bulk, but of like intensity.

On Thursday morning Professor Woodworth reported for Columbia. He referred briefly to investigations of a statistical nature, to an investigation on reading, to others on practice, on the relation of the position of the body to mental activity, on reaction times, on color mixing and on the capacity for learning as shown in the behavior of paramecium. He also reported more fully an investigation of the cue to voluntary movements. This investigation was carried on by means of introspection during various yoluntary acts. The results pointed to a mental state, having as its chief element something different from the sensational or motor content and corresponding on the physiological side to processes in the association areas. Dr. Baird reported for Johns Hopkins. He described an investigation on the reverse of the weight illusion, in which the size remained constant and the weight varied, and a study of the perception of direction during movements of varying amplitude on the skin. He reported more fully an investigation of the relation of the pigmentation of the macula to the perception of color stimulating that region of the retina. Messrs. Cameron and Freeman of the Yale laboratory occupied the remainder of the morning session in reports of investigations on tonal production and distraction, and on writing. 
During the afternoon Professors Holt and Pierce and Dr. Porter made reports, and the equipment of the Yale laboratory was inspected. Professor Pierce reported an investigation on stereoscopic fusion. $\mathrm{He}$ found that in the large majority of the cases which he investigated stereoscopic fusion did not take place and there was either false or equivocal interpretation. Dr. Porter reported a continuation of his investigations on the variability of instinct in nest-building spiders, and an investigation on reasoning in abnormal subjects. Professor Holt's report dealt with the thresholds of depth recognition through changes in convergence, with color vision in the immediate neighborhood of the blind spot and with the effect of variations of pitch on the localization of sounds. During the session the exercises which make up the experimental course at Yale were described and the apparatus used in this course was demonstrated. Professor Dodge also demonstrated the exposure apparatus with which he made the investigation on visual recognition above mentioned. It was so arranged that successive fields could be exposed by transfer of light from one to the other by mirrors, without motion of the field.

The following members were present and participated in the discussions, though they presented no reports: Dr. Yerkes, Professors Thorndike and Davis.

The invitation of Professor Witmer to hold the next meeting at the University of Pennsylvania was unanimously accepted.

YaLe UNIVERSTT:

Frank N. Freeman.

\section{BOOKS RECEIVED FROM APRIL 5 TO MAY 5 .}

Le sentiment et la pensée. A. Godfernaux. ze éd. revue. Paris, Alcan, 1906. Pp. 205. Fr. 2.50.

Idées générales de Psychologie. G. H. Luquet. Paris, Alcan, 1906. Pp. 295. Fr. 5.

Congress of Arts and Science. Vol. II. Politics, Law and Religion. Vol. III. Language, Literature and Art. Ed. by $\mathrm{H}$. J. Rogrrs. Boston, Houghton, Mifflin \& Co., ı906. Pp. 66r and 680. \$2.50 each.

Enigmas of Psychical Research. J. H. HysLop. Boston, Turner \& Co., .1906. Pp. xi +427 .

On Life after Death. G. T. Fechner. Trans. by H. Wernecke. New ed. Chicago, Open Court Co., r9o6. Pp. ${ }^{3} 35$. 